\title{
Synthesis and application of dual functionalized task specific ionic liquid for bamboo dissolution
}

\author{
Nor Shahroon Hameed Sultan ${ }^{1, *}$, Lethesh Kallidanthiyil Chellappan ${ }^{2}$, Wan Suzaini Wan Hamzah ${ }^{1}$, Leveque Jean \\ Marc $^{3}$ and Mohamed Ibrahim Abdul Mutalib ${ }^{1}$. \\ ${ }^{1}$ Centre of Research of Ionic Iiquid, University Teknologi Petronas, 32610 Seri Iskandar, Perak, Malaysia \\ ${ }^{2}$ Centre for Biofuel \& Biochemical, University Teknologi Petronas, 32610 Seri Iskandar, Perak, Malaysia \\ ${ }^{3}$ Université de Savoie Mont-Blanc, 73376 Le Bourget du Lac cede
}

\begin{abstract}
A new class of dual functionalized imidazolium based ionic liquid (IL) namely 3(2-cyano-ethyl)-1-(2-ethoxy-ethyl)-3-imidazolium bromide [CNEIM][Br], was synthesized and characterized to study their potential in bamboo dissolution. The chemical structure for the IL was characterized using NMR $\left({ }^{1} \mathrm{H}\right.$ and $\left.{ }^{13} \mathrm{C}\right)$. Thermal properties, surface morphology and functional group of the native bamboo and IL treated bamboo were analyzed by Thermal Gravimetric Anaylysis (TGA), Scanning Electron Microscopy (SEM) and Fourier Transform Infrared Spectroscopy (FTIR) respectively. The new IL was able to dissolve up to $5 \mathrm{wt} \%$ of bamboo biomass within 48 hours and $100^{\circ} \mathrm{C}$.
\end{abstract}

\section{Introduction}

Presently, the world facing of deficiency of nonrenewable resources such as coal, petroleum and natural gas. Hence, it is necessary to utilize renewable resources to fulfill the energy needs of our society [1]. Cellulosic biomass is one of the possible alternatives to petroleumbased feedstocks for fuels and chemicals because it is renewable, abundant, and inexpensive [2]. Cellulose comprise of recalcitrant polymer of 1-4 linked $\beta$-dglucose repetitive units with inter- and intramolecular hydrogen bonding [3]. It is very hard to convert cellulose into biofuels and biochemical because its recalcitrant nature due to the presence of inter and intramoleculer H-bonding network. In recent years, significant efforts have been made to develop new techniques for the conversion of cellulose into biofuels and platform chemicals $[4,5]$. Numerous pre-treatment procedures such as alkaline and acid pretreatment, ammonia fiber explosion and steam treatment have been established for the utilization of biomass [6]. However, an effective, inexpensive and sustainable process still needs to be developed. Recently, pretreatment of biomass using ionic liquids (ILs) has appeared as an alternative to the conventional methods due to its high capacity and capability.
Ionic liquids (ILs) are molten salts that are entirely ionic in nature, containing both cationic and anionic species and mostly having a melting point below $100{ }^{\circ} \mathrm{C}$ $[7,8]$. The choice of cations and anions has a large influence on their properties. Hence, by changing the cation or anion of the ILs, their physical properties can be tailored per the requirements of a process. These properties include melting point, density, viscosity, solubility and hydrophobicity. ILs is unique due to their certain remarkable properties which differentiate them from conventional organic solvents. They have a very low vapor pressure, wide liquids range, flammability and recyclability property $[9,10]$. ILs has been recently investigated for a wide range of potential applications such as catalytic synthesis [11], nanotechnology [12] and electrolytes for dye-sensitized solar cell [13]. Functionalized ILs may be defined as ionic liquids in which a functional group is covalently attached either to the cation or to the anion or even to both. The advantage of introducing a functional group into ILs is the fine-tuning of their properties for a particular application.

The types of anions and cations and functional groups attached to the cations/anions can affects the biomass dissolution potential of ILs. Imidazolium-based ILs has been used widely for dissolution of hardwoods and softwoods [14]. Some of the ILs cation increase the

* Corresponding author: norshahroon23@gmail.com 
cellulose dissolution by forming hydrogen bonds with the hydroxyl and ether oxygen of cellulose [3]. Besides, cyano (nitrile) group shows better dissolution ability compared to allyl group because of its smaller size and electron withdrawing nature [10].

The attachment of ether / PEG functional group to the side chain of imidazole cation would results in lowering the viscosity of IL compared to simple alkyl side chain [15]. Researcher has shown that hydrogen bond accepting ability of the IL anions related to its ability to dissolve cellulose. ILs containing anions with H-bond acepting ability such as chloride, formate, acetate or alkylphosphonate showed high biomass dissolution potential [16].

The present work focus on designing a new functionalized ILs containing nitrile and ether group for the dissolution of bamboo biomass. Bamboo was selected for this research due to the widely available in Malaysia. Besides, bamboo is very cheap, renewable and sustainability properties [17]. In this work, 3-(2-cyanoethyl)-1-(2-ethoxy-ethyl)-3-imidazolium bromide was successfully synthesized and characterized. The synthesized ionic liquid was finally tested for the biomass dissolution process.

\section{Experimental}

\subsection{Materials and Chemicals}

Acetone, 99\%, 2-bromoethyl ether, 90\%, and imidazole, $99 \%$, were acquired from Sigma Aldrich. Chloroform, $99.8 \%$ acyrolinitrile, $99 \%$, and ethyl acetate, $99.8 \%$ was purchased from Fisher Scientific. Bamboo (Gigantochloa scortechini) was gained from local market in Perak, Malaysia. The bamboo size was standardise using Restesh Test sieve less than $500 \mu \mathrm{m}$. All chemicals (analytical reagent grade) were commercially obtained and used without further purification unless otherwise stated.

\subsection{Synthesis of Propionitrile imidazole}

Imidazole $(0.74 \mathrm{~mol}, 50 \mathrm{gm})$ was dissolved in chloroform $(50 \mathrm{~mL})$ in a round bottom flask and acrylonitrile $(0.74 \mathrm{~mol}, 38 \mathrm{gm})$ was added dropwise and stirred for 48 hours at $65^{\circ} \mathrm{C}$. The viscous liquid was cooled and dried using rotary evaporator. Yield about (68g) 77\%.

\subsection{Synthesis of 3-(2-cyano-ethyl)-1-(2-ethoxy- ethyl)-3-imidazolium bromide [CNEIM][Br]}

The propionitrile imidazole $(0.41 \mathrm{~mol}, 50 \mathrm{gm})$ was added to 2-bromoethyl ether $(0.41 \mathrm{~mol}, 63 \mathrm{gm})$ and stirred at $85^{\circ} \mathrm{C}$ for 72 hours. The viscous ionic liquid was washed with ethyl acetate $(4 \times 20 \mathrm{~mL})$. The residue is dried using rotary evaporator. Yield about (90g) 79\%.

\subsection{Characterization for IL}

${ }^{1} \mathrm{H}$ and ${ }^{13} \mathrm{C}$ NMR spectrum of the IL are recorded on a Bruker Avance 500 spectrometer. ${ }^{1} \mathrm{H}-\mathrm{NMR}$ (500Mhz, DMSO-d6): $\delta=9.297(\mathrm{~s}, 1 \mathrm{H}), 7.887(\mathrm{~d}, 2 \mathrm{H}), 4.566(\mathrm{t}, 2 \mathrm{H})$, $4.415(\mathrm{t}, 2 \mathrm{H}), \quad 3.740(\mathrm{~m}, 2 \mathrm{H}), \quad 3.473(\mathrm{t}, 2 \mathrm{H}), \quad 3.268(\mathrm{t}, 2 \mathrm{H})$, $1.093(\mathrm{t}, 3 \mathrm{H}) . \quad{ }^{13} \mathrm{C}-\mathrm{NMR} \quad(125.77 \mathrm{Mhz}, \mathrm{DMSO}-\mathrm{d} 6)$ : $\delta=137.28,123.65,122.76,118.16,67.86,66.05,49.61$, $44.93,19.13,15.30$.

Thermogravimetric analysis is using Perkin Elmer STA600 analyser is carried out on an average of 5-10 $\mathrm{mg}$ of samples. The experiment is carry out at a constant heating rate of $10{ }^{0} \mathrm{C} / \mathrm{min}$ from 50 to $800{ }^{0} \mathrm{C}$ in inert atmosphere (pure nitrogen).

\subsection{Bamboo dissolution}

The bamboo (2wt \%, 3wt \%, 4wt \%, 5wt \%) was mixed with 3 gram of IL in $12 \mathrm{~mL}$ vial. The mixture was then stirred at $100^{\circ} \mathrm{C}$ for 48 hours using hotplate. The temperature of bamboo dissolution experiment was controlled by using oil bath. The solubility of bamboo in IL was checked visually after 48 hours by using a handheld microscope, Dino-lite Pro AM413T. After complete dissolution of bamboo, acetone $(5 \times 10 \mathrm{~mL})$ was added to regenerated cellulose. The regenerated cellulose was filtered and washed with water to remove any trace of ILs. The cellulose was dried in an oven at $60^{\circ} \mathrm{C}$ for 48 hours.

\subsection{Characterization for regenerated bamboo}

The spectra of the samples was recorded on a FTIR spectrometer model Nicolet iS5 which is equipped with an attenuated total reflectance (ATR) unit (Thermo Scientific). The spectra was conducted over the range of 4000 to $500 \mathrm{~cm}^{-1}$.

The morphology of untreated and treated bamboo was obtained using a Hitachi TM 3030 model scanning electron microscope (SEM) operated at $15 \mathrm{kV}$ accelerating voltage. The free and fracture surfaces of the film are sputtered with gold, and then observed and photographed. The samples are sputter coated with gold before analysis to avoid electrical charging of the samples during micrographs by using Quorum SC 7620 sputter coater. The TGA of untreated and treated bamboo was carry out at a constant heating rate of 10 ${ }^{0} \mathrm{C} / \mathrm{min}$ from 50 to $800{ }^{0} \mathrm{C}$ in inert atmosphere (pure nitrogen).

\section{Result and discussion}

\subsection{Thermal properties of [CNEIM][Br]}




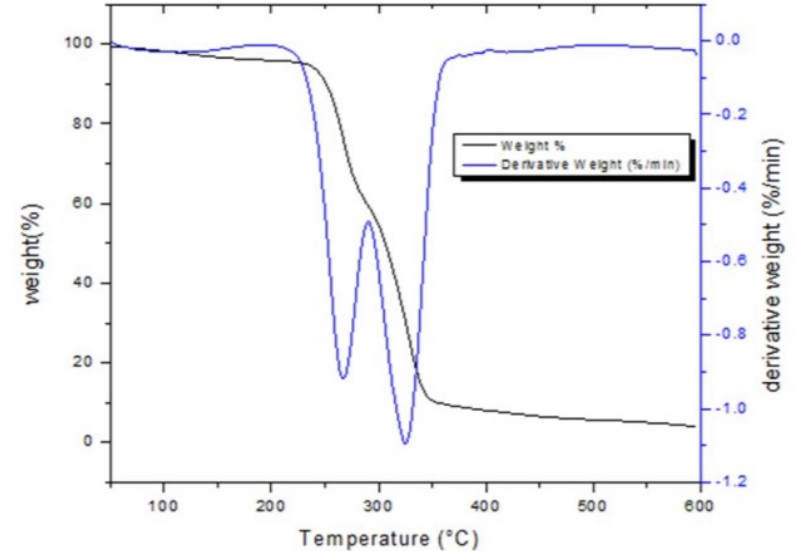

Fig. 1. TGA for [CNEIM] $[\mathrm{Br}]$

The TGA profile displaying the thermal decomposition of [CNEIM] $[\mathrm{Br}]$ is shown in Fig. 1. As shown in Fig. 1, there are two thermal decomposition temperature noticed. The decomposition temperature of [CNEIM][Br] IL are at $248.89{ }^{\circ} \mathrm{C}$ and $306.50{ }^{\circ} \mathrm{C}$. According to, Liang et al [18] the two-thermal decomposition is due to the anion. This indicates that the IL is highly stable and suitable for reaction that require high or extreme temperature.

\subsection{Bamboo Dissolution}

The dissolution of bamboo in [CNEIM][Br] IL was studied at different condition. Each mixture of bamboo and IL was heated at $100^{\circ} \mathrm{C}$ for 48 hour with different loading of bamboo from $1 \mathrm{wt} \%$ to $5 \mathrm{wt} \%$. After heating for 48 hour at $100^{\circ} \mathrm{C}$ and under vigorous stirring. The microscopic visual changes of bamboo before and after the dissolution process was observed and showed in Fig 2. From the microscopic visual of bamboo dissolution, it can see that there was brownish fiber. Meanwhile after the dissolution it can see that a clear liquid. Thus, it shows that [CNEIM][Br] IL could dissolve bamboo at $100{ }^{\circ} \mathrm{C}$ within $48 \mathrm{hr}$. Swatloski et al. [20] conduct a study on cellulose dissolution using 1-butyl-3methylimidazolium $([\mathrm{Bmim}]+)$ cation with different combination of anion which are $\mathrm{Cl}^{-}, \mathrm{PF}_{6}{ }^{-}, \mathrm{Br}^{-}, \mathrm{SCN}^{-}$, and $\mathrm{BF}_{4}^{-}$. It shows that only $\mathrm{Cl}^{-}, \mathrm{SCN}^{-}$and $\mathrm{Br}^{-}$anion containing ionic liquids could dissolve cellulose at 100 to $110{ }^{\circ} \mathrm{C}$. The dissolved biomass was precipitated by adding acetone and the biomass was filtered using filter paper. The biomass was washed with water till the complete removal of ILs. The ILs was regenerated by evaporating the solvent under vacuum. The regenerated ionic liquid was successfully characterized using ${ }^{1} \mathrm{HNMR}$ and no changes in the structure is observed Fig. 3.

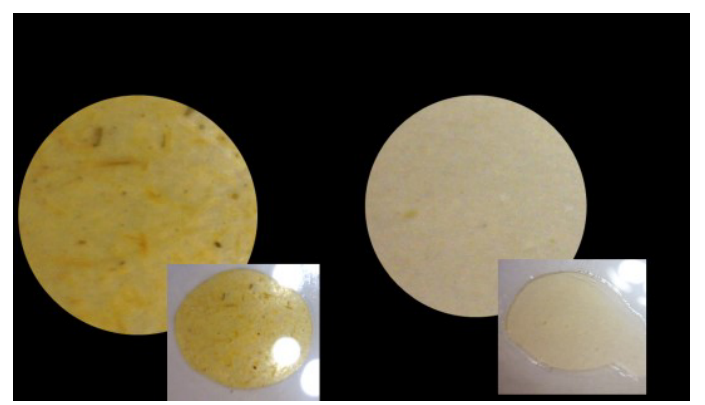

Fig. 2. Microscopic visual changes of bamboo before and after dissolution process.

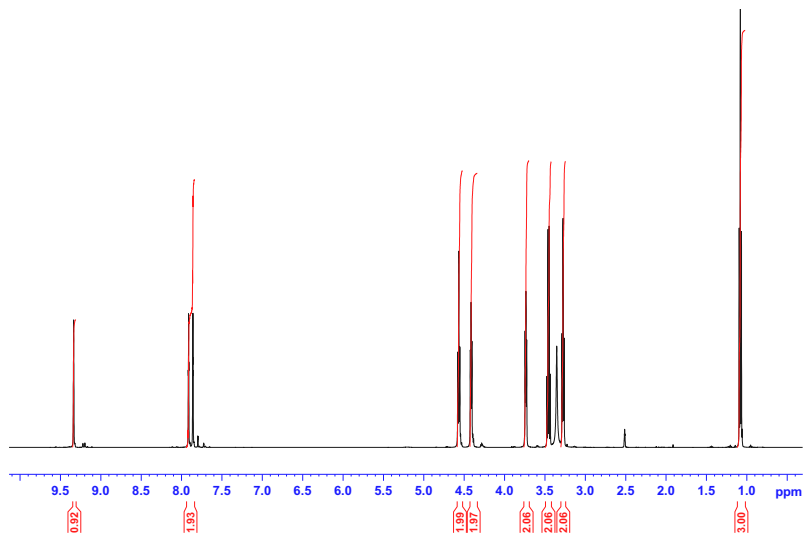

Fig. 3. ${ }^{1} \mathrm{H}-\mathrm{NMR}$ for regenerated [CNEIM] $[\mathrm{Br}]$

The capability of the IL to dissolve bamboo is confirmed by studying the morphology of bamboo after the dissolution (Fig. 4). The IL treated bamboo showed a significant amendment in morphology compared to the untreated bamboo. The untreated bamboo seemed to have a circular [21], rough surface and compact. Similar observation was reported by using oil palm biomass treated with 1-ethyl-3-methylimidazolium-diethyl phosphate IL. According to Financie et al. [22] it might be due to the lignin covered on cellulose and hemicellulose. The treated bamboo showed modification in the fiber where there is a crack and curly structure $[23,24]$. This shows that the [CNEIM][Br] IL was completely disrupting the cell wall of bamboo. 


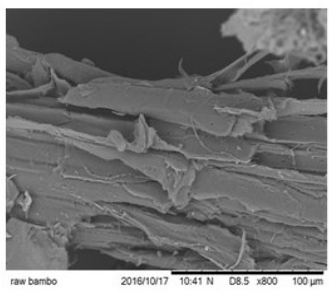

a

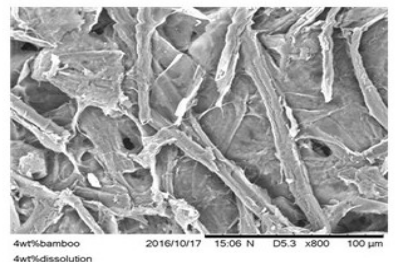

d

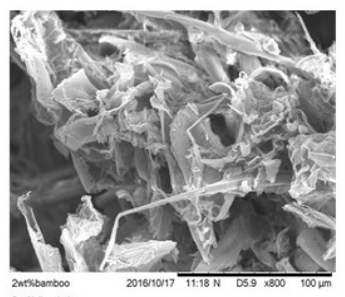

b

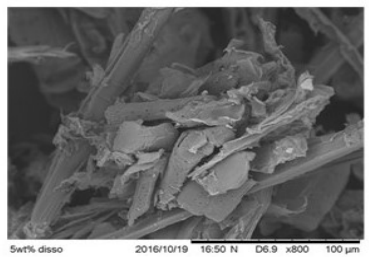

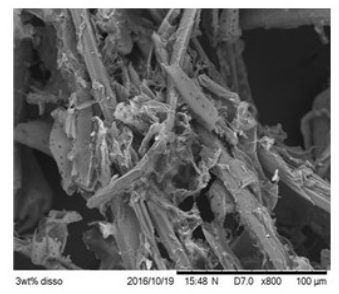

C

Fig. 4. Morphology of (a) untreated bamboo (b) treated bamboo at $2 \mathrm{wt} \%$ (c) treated bamboo at $3 \mathrm{wt} \%$ (d) treated bamboo at $4 \mathrm{wt} \%$ (e) treated bamboo at $5 \mathrm{wt} \%$.

FTIR analysis was conducted to analyze any structural changes on bamboo during IL treatment. The FTIR spectra of the untreated and treated bamboo are shown in Fig. 5. The FTIR spectrum of treated and untreated bamboo is found to be similar. The presence of hydroxyl, carbonyl, methoxyl and carboxyl functional groups have been reported for identification of lignin [24]. A broad band of hydroxyl and methoxyl groups are observed around $3336 \mathrm{~cm}^{-1}$ and $2895 \mathrm{~cm}^{-1}$ respectively. The strong intensity bands at 1602 to $1504 \mathrm{~cm}^{-1}$ was attribute to the aromatic skeleton from lignin component $[17,25,26,27]$. The peak value at $1240 \mathrm{~cm}^{-1}$ is due to phenol ether bonds of lignin while $1158 \mathrm{~cm}^{-1}$ and $1031 \mathrm{~cm}^{-1}$ are due to structural contribution of cellulose and hemicellulose [26]. A band of range (896 - 561) $\mathrm{cm}^{-1}$ represent the alkane group $(\mathrm{CH}-\mathrm{CH})$ and the deformation of cellulose [26].

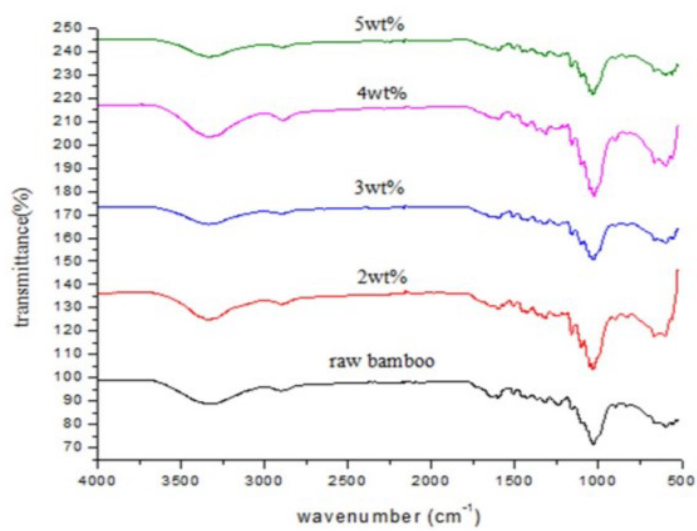

Fig. 5. FTIR spectra for untreated and treated bamboo

The thermal stability of treated and untreated bamboo was determined using TGA analysis. The thermogram of treated and untreated bamboo was shown in Fig. 6. The results showed the thermal stability of the bamboo reduce after the IL pretreatment. The decomposition of the treated and untreated bamboo could be divided into three stage. The first stage involved moisture evaporation at around $150^{\circ} \mathrm{C}$, measured at $4 \mathrm{wt} \%$ loading. This is followed by the decomposition of the hemicellulose at around $300^{\circ} \mathrm{C}[28$, 29]. Hemicellulose can be categorized as the most reactive and easily degrade constituent compared to cellulose and lignin. In the third stage, which covers the temperature range from 350 to $400^{\circ} \mathrm{C}$, represents the thermal degradation of the cellulose. This is due to higher amount of hydrogen bonds existed between cellulose chains which leads to more ordered and packed cellulose regions [30]. The temperature range between 300 and $600^{\circ} \mathrm{C}$ is due to the weight loss stage of lignin composition in bamboo [31].

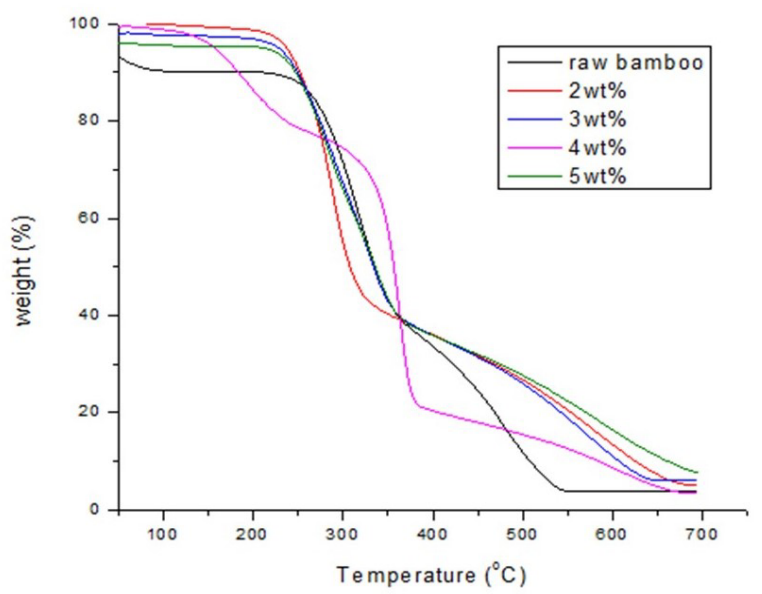

Fig. 6. TGA curve untreated and treated bamboo.

\footnotetext{
*Corresponding author: norshahroon23@gmail.com
} 
Table 1. Thermal decomposition of untreated and treated bamboo

\begin{tabular}{|c|l|l|}
\hline Biomass loading & Thermal decomposition $\left({ }^{\circ} \mathrm{C}\right)$ \\
\hline Raw bamboo & 269.25 & 469.73 \\
\hline $2 w t \%$ & 244.18 & 470.50 \\
\hline $3 w t \%$ & 238.93 & 491.63 \\
\hline $4 w t \%$ & 319.72 & 493.94 \\
\hline $5 w t \%$ & 220.25 & 469.73 \\
\hline
\end{tabular}

Fig. 7 showed the differential thermal gravimetric (DTG) curve for untreated and treated bamboo. DTG shows that at $4 \mathrm{wt} \%$ of bamboo dissolution shows a high thermal stability compared to untreated bamboo, $2 \mathrm{wt} \%$, $3 w t \%$ and $5 w t \%$. The present of two distinct peaks in DTG is due to the degradation of hemicellulose followed by cellulose [31]. The thermal degradation between 400 and $600^{\circ} \mathrm{C}$ may be due to degradation of lignin [32].

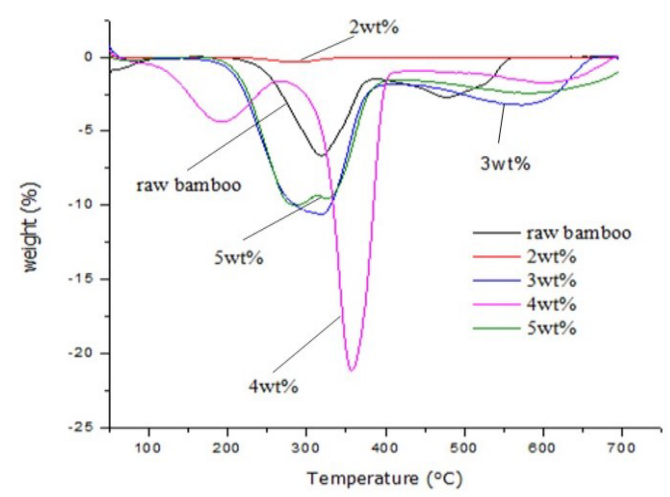

Fig. 7. DTG curve for untreated and treated bamboo.

\section{Conclusion}

Synthesizing and characterizing of [CNEIM][Br] has been successfully achieved. Based on the analyzed data, this type of IL with nitrile and ether functionalized group, is proven to have the potential and capability of dissolving the bamboo and the dissolution capacity can reach up to $5 \mathrm{wt} \%$. There is no degradation of ILs was observed after the dissolution process. Moreover, significant changes was occurred after pretreatment with IL.

The authors would like to thank to center of research in ionic liquid and also FRGS grant for financial support.

\section{References}

[1] Beltramino, F., Roncero, M. B., Vidal, T., Torres, A. L., \& Valls, C. (2015). Increasing yield of nanocrystalline cellulose preparation process by a cellulase pretreatment. Bioresour. Technol., 192, 574581 .
[2] Minnick, D. L., \& Scurto, A. M. (2015). Reversible and non-reactive cellulose separations from ionic liquid mixtures with compressed carbon dioxide. Chem. Commun., 51(63), 12649-12652.

[3] Ibrahim, F., Moniruzzaman, M., Yusup, S., \& Uemura, Y. (2015). Dissolution of cellulose with ionic liquid in pressurized cell. J. Mol. Liq., 211, 370-372.

[4] Christensen, C. H., Rass-Hansen, J., Marsden, C. C., Taarning, E., \& Egeblad, K. (2008). The Renewable Chemicals Industry. ChemSusChem, 1(4), 283-289.

[5] Gallezot, P. (2008). Catalytic Conversion of Biomass: Challenges and Issues. ChemSusChem, 1(8-9), 734-737.

[6] Xu, J., Xiong, P., \& He, B. (2016). Advances in improving the performance of cellulase in ionic liquids for lignocellulose biorefinery. Bioresour. Technol, 200, 961-970.

[7] An, Y., Zong, M., Wu, H., \& Li, N. (2015). Pretreatment of lignocellulosic biomass with renewable cholinium ionic liquids: Biomass fractionation, enzymatic digestion and ionic liquid reuse. Bioresour.Technol, 192, 165-171.

[8] Lee, H. V., Hamid, S. B., \& Zain, S. K. (2014). Conversion of Lignocellulosic Biomass to Nanocellulose: Structure and Chemical Process. The Scientific World Journal, 2014, 1-20.

[9] Socha, A. M., Parthasarathi, R., Shi, J., Pattathil, S., Whyte, D., Bergeron, M., Singh, S. (2014). Efficient biomass pretreatment using ionic liquids derived from lignin and hemicellulose. PNAS, 111(35).

[10] Badgujar, K. C., \& Bhanage, B. M. (2015). Factors governing dissolution process of lignocellulosic biomass in ionic liquid: Current status, overview and challenges. Bioresour. Technol., 178, 2-18.

[11] Cocalia, V., Gutowski, K., \& Rogers, R. (2006). The coordination chemistry of actinides in ionic liquids: A review of experiment and simulation. Coor. Chem. Rev., 250(7- 8), 755-764.

[12] Wang, P., Wenger, B., Humphry-Baker, R., Moser, J., Teuscher, J., Kantlehner, W,. Grätzel, M. (2005). Charge Separation and Efficient Light Energy Conversion in Sensitized Mesoscopic Solar Cells Based on Binary Ionic Liquids. J. Am. Chem. Soc., 127(18), 6850-6856.

[13] Wang, P., Zakeeruddin, S. M., Moser, J., HumphryBaker, R., \& Grätzel, M. (2004). A Solvent-Free, SeCN - /(SeCN) 3 - Based Ionic Liquid Electrolyte for HighEfficiency Dye-Sensitized Nanocrystalline Solar Cells. J. Am. Chem. Soc., 126(23), 7164-7165.

[14] Mora-Pale, M., Meli, L., Doherty, T. V., Linhardt, R. J., \& Dordick, J. S. (2011). Room temperature ionic liquids as emerging solvents for the pretreatment of lignocellulosic biomass. Biotechnol. Bioeng., 108(6), 1229-1245.

[15] Kuhlmann, E., Himmler, S., Giebelhaus, H., \& Wasserscheid, P. (2007). Imidazolium Dialkylphosphates - A Class of Versatile, HalogenFree and Hydrolytically Stable Ionic Liquids. ChemInform, 38(30).

[16] Mood, S. H., Golfeshan, A. H., Tabatabaei, M., Jouzani, G. S., Najafi, G. H., Gholami, M., \& Ardjmand, M. (2013). Lignocellulosic biomass to bioethanol, a 
comprehensive review with a focus on pretreatment. Renewable Sustainable Energy Rev., 27, 77-93.

[17] Bhat,I., Mustafa, M.T., Mohmod, A. L., Khalil., (2011) Spectroscopic, Thermal, And Anatomical Characterization Of Cultivated Bamboo (Gigantochloa Spp.) Bioresour. Technol., 6(2), 1752-1763.

[18] Liang, H.F, Li, G.J, Gou, G.J., \& Wang, A.Q. (2013). Study of Preparation and Thermal Stability of CyanoFunctionalized Imidazolium Type Ionic Liquids., Asian J. Chem., 25(9), 4779-4782.

[19] Sun, N., Rahman, M., Qin, Y., Maxim, M. L., Rodríguez, H., Rogers, R. (2009) Green Chem.,11, 646655.

[20] R. P. Swatloski, S. K. Spear, J. D. Holbrey, R. D. Rogers, (2002). J. Am. Chem. Soc., 124, 4974- 4975.

[21] Yang, Z., Xu, S., Ma, X., \& Wang, S. (2008). Characterization and acetylation behavior of bamboo pulp. Wood Sci And Technol, 42(8), 621-632.

[22] Financie, R., Moniruzzaman, M., \& Uemura, Y. (2016). Enhanced enzymatic delignification of oil palm biomass with ionic liquid pretreatment. Biochem. Eng. J., 110, 1-7.

[23] Hernández-Mena L., Pecora A., Beraldo A., 2014, Slow pyrolysis of bamboo biomass: analysis of biochar properties, Chem. Eng. Trans, 37, 115-120.

[24] Jiang, Z., Miao, J., Yu, Y., \& Zhang, L. (2016). Effective Preparation of Bamboo Cellulose Fibers in Quaternary Ammonium/DMSO Solvent. Bioresources, 11(2).

[25] Muhammad, N., Man, Z., Bustam, M. A., Mutalib, M. A., \& Rafiq, S. (2013). Investigations of novel nitrile-based ionic liquids as pre-treatment solvent for extraction of lignin from bamboo biomass. J. Ind. Eng. Chem., 19(1), 207-214.
[26] Xu, G., Wang, L., Liu, J., \& Wu, J. (2013). FTIR and XPS analysis of the changes in bamboo chemical structure decayed by white-rot and brown-rot fungi. Appl. Surf. Sci., 280, 799-805.

[27] Liew, F. K., Hamdan, S., Rahman, M. R., Rusop, M., Lai, J. C., Hossen, M. F., \& Rahman, M. M. (2015). Synthesis and Characterization of Cellulose from Green Bamboo by Chemical Treatment with Mechanical Process. J. Chem., 1-6.

[28] Zhang, X., Wang, F., \& Keer, L. (2015). Influence of Surface Modification on the Microstructure and Thermo-Mechanical Properties of Bamboo Fibers. Materials, 8(10), 6597-6608.

[29] Wang, Q., Chen, Q., \& Endo, T. (2015). Thermal Decomposition of Bamboo Phyllostachys Edulis Pretreated with Ionic Liquids-Water Mixtures. Green and Sustainable Chemistry GSC, 05(02), 55-62.

[30] Meenatchi, B., Renuga, V., \& Manikandan, A. (2016). Cellulose dissolution and regeneration using various imidazolium based protic ionic liquids. J. Mol. Liq.

[31] Gordobil, O., Moriana, R., Zhang, L., Labidi, J., \& Sevastyanova, O. (2016). Assesment of technical lignins for uses in biofuels and biomaterials: Structure-related properties, proximate analysis and chemical modification. Industrial Crops and Products, 83, 155165.

[32] Strydom, C., Sehume, T., Bunt, J., \& van Dyk, J. (2015). The influence of selected biomass additions on the co-pyrolysis with an inertinite-rich medium rank $\mathrm{C}$ grade South African coal. J. South. Afr Inst. Min. Metallu., 115(8), 707-716. 